\title{
Effect of Deformation Condition on Microstructure and Mechanical Properties of Aluminum Alloy Tube in Cyclic Rotating Bending Process
}

\author{
Zicheng Zhang ${ }^{1,3, a^{*}, \text { Shuai Shao }}{ }^{1, b}$, Peng Huang ${ }^{2, c}$ and Ken-ichi Manabe ${ }^{3, d}$ \\ ${ }^{1}$ School of Mechanical Engineering and Automation, P.O. Box 319, Northeastern University, No. 11 \\ Lane 3, Wenhua Rd, Heping District, Shenyang 110819, Liaoning Province, PR China \\ ${ }^{2}$ Shanghai Baosteel Hydroforming Parts Co., Ltd, No. 188 LuoChun Rd, 201908, Shanghai, P. R. \\ China \\ ${ }^{3}$ Department of Mechanical Engineering, Tokyo Metropolitan University, 1-1 Minami-Osawa, \\ Hachioji-shi, Tokyo, Japan \\ azhangzicheng2004@126.com, ’ss86252461@163.com, chuangpengneu@163.com, \\ * Corresponding author
}

Keywords: cyclic rotating bending process, microstructure refinement, mechanical properties, metal tube, severe plastic deformation.

Abstract. To refine the microstructure and improve the mechanical properties of the metal tubes, a new kind of severe plastic deformation process of the cyclic rotating bending (CRB) process was newly proposed. This study focused on the investigation of evolution of microstructure and mechanical properties of aluminum alloy (6061) tube in the CRB processes with different bending angles and deformation temperatures. The tensile test was employed to evaluate the mechanical properties of the tube after deformation, and Optical Microscopy were utilized for the microstructure characterizations. The results showed that the temperature and bending angle have a strong influence on the mechanical properties and microstructure of the specimens processed by the CRB process. As a result that the aluminum alloy (6061) tube with a grain size of $86 \mathrm{um}$ as well as ultimate tensile strength of $244 \mathrm{MPa}$ and total elongation of $10.05 \%$ was successfully obtained with the optimized deformation condition of the $\mathrm{CRB}$ process with a temperature of $100^{\circ} \mathrm{C}$ and bending angle of $170^{\circ}$, when the rotation speed and deformation time were fixed at $20 \mathrm{rpm}$ and $5 \mathrm{~min}$, respectively.

\section{Introduction}

Improving the fuel efficiency is an effective way to reduce the environmental impact of using fossil fuel. For this purpose, the use of aluminum alloys hollow structures to decrease the overall weight of the mechanism implemented within the transportation devices has been receiving an increasing attentions. However, the low strength of aluminum alloys has limited their extensive use in industry. On the other hand, the severe plastic deformation (SPD) process has been used to refine the microstructure and improve the mechanical properties of metallic materials. The SPD processes such as Equal Channel Angular Extrusion (ECAE) [1], Repetitive Side Extrusion [2], Rotary-die ECAP [3], Parallel Channel ECAP [4], Accumulative Roll-Bonding (ARB) [5], High-Pressure Tube Twisting (HPTT) [6], and Twist Extrusion (TE) [7] etc. have been used in metallurgy research field. However, the special tools or dies are required to realize these SPD processes. In addition, most of the SPD processes focused on the microstructure refinement of metal bars. To manufacture the metal tube with fine microstructure and good mechanical properties of the authors newly proposed a new SPD process of cyclic rotating bending (CRB) process [8]. The present study focused on investigating the effect of deformation conditions of the CRB process on microstructure and mechanical properties of aluminum alloy (6061) tube. This experiment is intended to pick out the optimized deformation temperature and bending angle of the CRB process for the aluminum alloy tubes. 


\section{Experimental Procedure}

The aluminum alloy (6061) tubes with an outer diameters of $10 \mathrm{~mm}$, thickness of $2 \mathrm{~mm}$ and length of $200 \mathrm{~mm}$ were used in the current study. Fig. 1 shows newly proposed SPD equipment of the CRB process used in this study. The rotation speed of the tube is fixed as 20rpm. The deformation time is $5 \mathrm{~min}$ for all the samples. As the comparison references, the aluminum alloy tubes were also heat-treated with the same temperatures for $5 \mathrm{~min}$. The deformation temperatures of $100^{\circ} \mathrm{C}, 150^{\circ} \mathrm{C}$ and $200^{\circ} \mathrm{C}$ were adopted to study the influence of deformation temperature on the microstructure and mechanical properties of aluminum alloy tube. In addition, to clarify the effect of bending angle on the evolution of microstructure and mechanical properties during the deformation process, the bending angles of $154^{\circ}, 160^{\circ}$ and $170^{\circ}$ were used in the CRB process. The optical microscope with a type of OLYMPUS BX51M was conducted to observe the microstructure. The grain size of the samples was obtained by the secant method. The tensile properties of the samples were attained with the conventional tensile test with a fixed cross head speed of $2.5 \mathrm{~mm} / \mathrm{s}$ at room temperature. The specimen for the tensile test were prepared according to the standard of GB/T 228.1-2010 with an initial gauge length of $50 \mathrm{~mm}$. A universal test machine with a type of SHIMADZU AG-50KN was used in the current study.

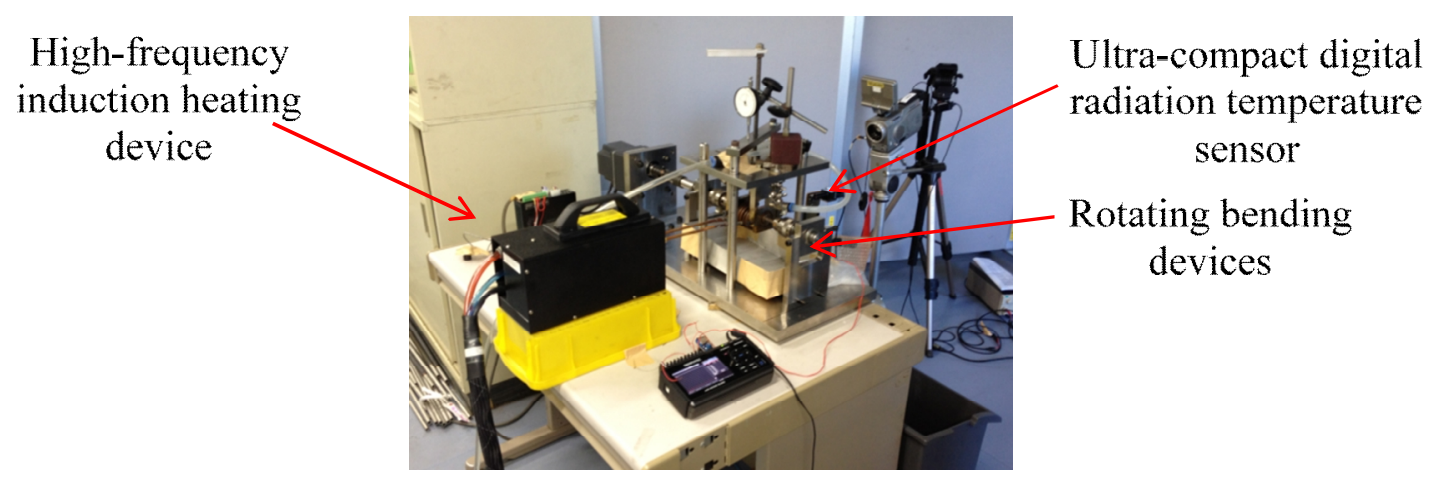

Fig.1. Newly proposed SPD equipment of the CRB process

\section{Results and Discussion}

Effect of deformation conditions on the microstructure of aluminum alloy tube. Fig. 2(a)-(d) compares OM maps of the specimens subjected to different bending angles of the CRB process with the deformation temperature of $100^{\circ} \mathrm{C}$. As can be seen in Fig.2 (a), the microstructure of the tube without bending deformation mainly consists coarse grains with an average grain size of $109 \mu \mathrm{m}$. From Fig.2 (b), it can be seen that a few of fine grains have appeared with an average grain size of $86 \mu \mathrm{m}$ when the bending angle is $170^{\circ}$, which implied alternation of the microstructure. When the bending angle is $160^{\circ}$, the average grain size of sample is $103 \mu \mathrm{m}$. In addition, similar microstructures can be seen for specimens when the bending angle is $154^{\circ}$ as illustrated in Fig.2 (d). Compared to the tube without deformation, the average grain size of the tubes decreased after the CRB process. As mentioned above, it indicated that the bending angle has a strong influence on the grain size of aluminum tube. When the bending angle is $170^{\circ}$, the sample with the smallest grain size can be obtained.

Fig. 3(a)-(c) compares OM maps of the tubes subjected to different deformation temperature of the $\mathrm{CRB}$ process with the bending angle of $170^{\circ}$. As illustrated in Fig. 3(a), the microstructure of the tube with the deformation temperature of $100^{\circ} \mathrm{C}$ mainly consists the grains with an average grain size of $85 \mu \mathrm{m}$. With the deformation temperature increasing from $100^{\circ} \mathrm{C}$ to $150^{\circ} \mathrm{C}$, the average grain size of the tube increase to $100 \mu \mathrm{m}$. Moreover, the average grain size is continuously increase to $105 \mu \mathrm{m}$ when the deformation temperature increased to $200^{\circ} \mathrm{C}$. As mentioned above, it indicated that the deformation temperature has a large influence on the grain size. The average grain size of the tube increased with the 
increase of deformation temperature from $100^{\circ} \mathrm{C}$ to $200^{\circ} \mathrm{C}$. When the deformation temperature is $100^{\circ} \mathrm{C}$, the tube with the smallest grain size was obtained.

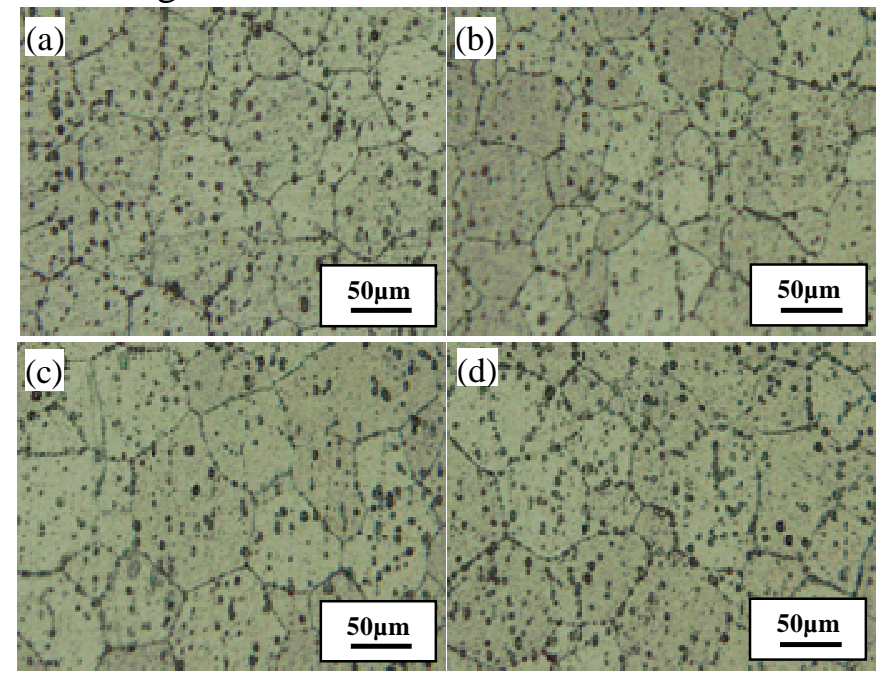

Fig. 2. OM images of the selected sample at $100^{\circ} \mathrm{C}$, (a) without bending, (b) $170^{\circ}$, (c) $160^{\circ}$, and (d) $154^{\circ}$.
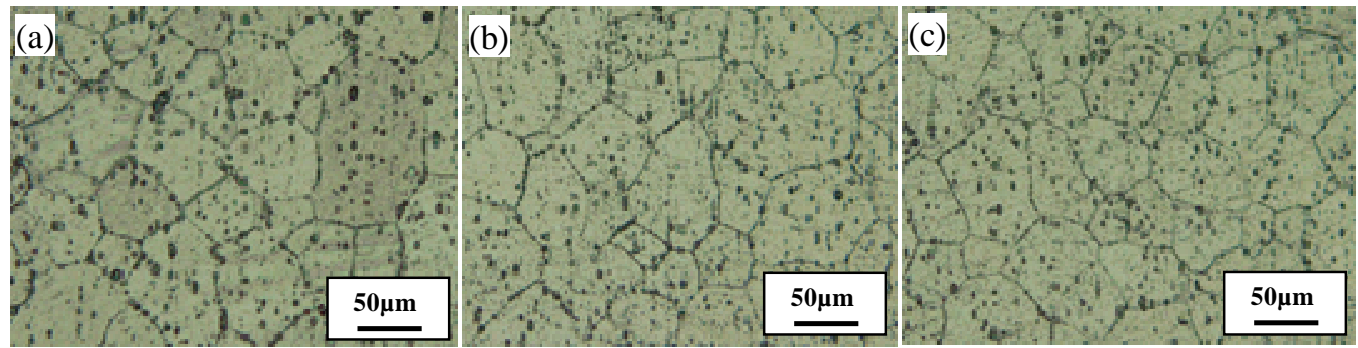

Fig. 3. OM images of sample (a) $100^{\circ} \mathrm{C}$ (b) $150^{\circ} \mathrm{C}$, and (c) $200^{\circ} \mathrm{C}$ when the bending angle of the $\mathrm{CRB}$ process is $170^{\circ}$.

Effect of deformation conditions on the mechanical properties of aluminum alloy tube. Fig. 4 illustrates the true stress vs. true strain curves of the samples after the CRB processes with different deformation conditions. Fig. 4(a) shows the effect of the bending angles on the mechanical properties of aluminum alloy tubes when the deformation temperature was fixed at $100^{\circ} \mathrm{C}$. The mechanical properties of the aluminum alloy tubes were improved by the CRB process which can be concluded by comparing the true stress vs. true strain curves with the aluminum alloy tube without deformation. When the bending angle is $170^{\circ}$, the yield strength, the ultimate tensile strength and elongation of the tubes show the highest values compared with those of the tubes after the CRB process with the bending angle of $154^{\circ}$.
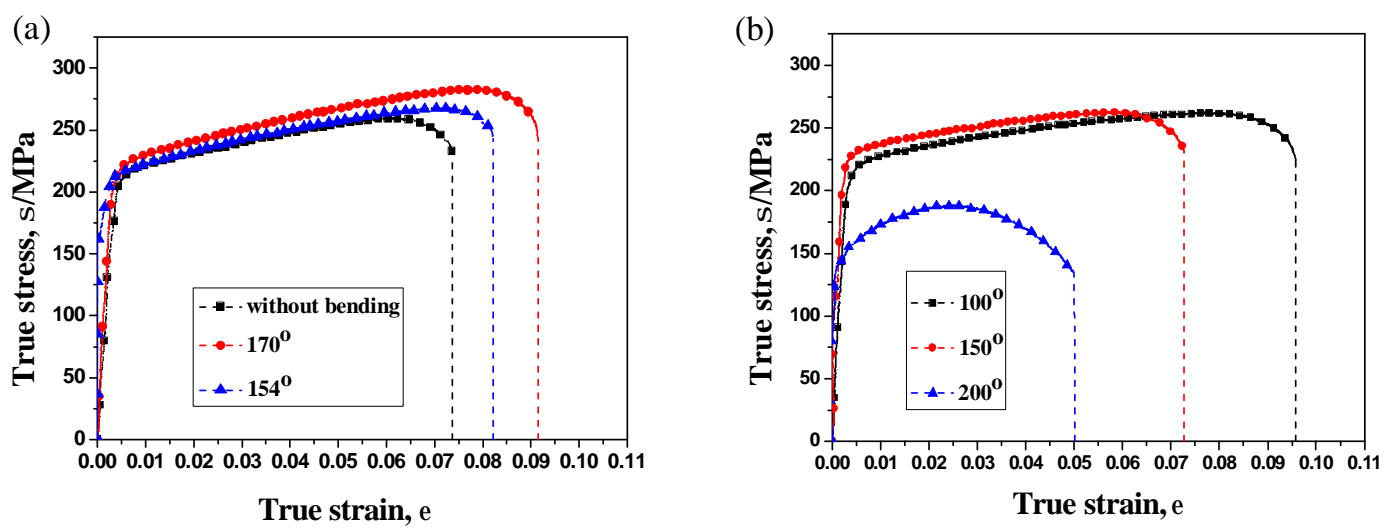

Fig. 4. Tensile properties of the processed aluminum alloy tubes at different deformation conditions by the $\mathrm{CRB}$ processes ((a) the deformation temperature is $100^{\circ} \mathrm{C}$ and $(\mathrm{b})$ the bending angle is $\left.170^{\circ}\right)$. 
Fig. 4(b) shows the mechanical properties of the aluminum alloy tubes processed by the CRB processes with different temperatures when the bending angle was set as $170^{\circ}$. The yield strength, ultimate tensile strength and total elongation show drastic decrease when the deformation temperature increase from $100^{\circ} \mathrm{C}$ to $150^{\circ} \mathrm{C}$. With further increase of the deformation temperature to $200^{\circ} \mathrm{C}$, the value of elongation continuously decreased, and the yield and ultimate tensile strength decreased obviously. Considering above, it can be inferred that the micro crack may appear in the deformed tube with the increasing of deformation temperature. The micro crack caused the poor mechanical properties of the aluminum alloy (6061) tube processed by the CRB process with the deformation temperature of $200^{\circ} \mathrm{C}$.

\section{Summary}

The effect of the deformation conditions of the CRB process on the evolution of microstructure and mechanical properties of aluminum alloy tube were studied in the present study. The results show that the temperature and bending angle have a strong influence on the mechanical properties and microstructure of the specimens processed by the CRB. As a result, the aluminum alloy tube with a grain size of 86 um as well as ultimate tensile strength of $244 \mathrm{MPa}$ and total elongation of $10.05 \%$ was successfully obtained with the optimized deformation condition of the CRB process with a temperature of $100^{\circ} \mathrm{C}$ and bending angle of $170^{\circ}$ when the rotation speed and deformation time were fixed at $20 \mathrm{rpm}$ and $5 \mathrm{~min}$, respectively.

\section{Acknowledgements}

This work was financially supported by the foundation of Project supported by the National Natural Science Foundation of China (Grant No. 51304046), Grant-in-Aid for Young Scientists (B) (Grant No. 25870594) of Japan Society for the Promotion of Science, Specialized Research Fund for the Doctoral Program of Higher Education, China (Grant No. 20130042120031) and the Scientific Research Starting Foundation for Introduced Talents of Northeastern University, PR China (Grant No. 02080021233061).

\section{References}

[1] V.M. Segal, Minsk, Russia (1974).

[2] A. Azushima, K. Aoki, Mechanical properties of ultrafine grained steel produced by repetitive cold side extrusion, CIRP Annals - Manufacturing Technology, 51 (2002) 227-230.

[3] Y. Nishida, H. Arima, J.C. Kim, T. Ando, Rotary-die equal-channel angular pressing of an Al-7 mass\% Si-0.35 mass\% Mg alloy, Scripta. Mater. 45 (2001) 261-266.

[4] F. Djavanroodi, M. Ebrahimi, Effect of die parameters and material properties in ECAP with parallel channels, Mater. Sci. Eng., A, 527 (2010) 7593-7599.

[5] Y. Saito, H. Utsunomiya, N. Tsuji, T. Sakai, Novel ultra-high straining process for bulk materials-development of the accumulative roll-bonding (ARB) process, Acta Mater, 47 (1999) 579-583.

[6] L.S. Tóth, M. Arzaghi, J.J. Fundenberger, B. Beausir, O. Bouaziz, R. Arruffat-Massion, Severe plastic deformation of metals by high-pressure tube twisting, Scripta Mater, 60 (2009) 175-177.

[7] Y. Beygelzimer, A. Reshetov, S. Synkov, O. Prokof'eva, R. Kulagin, Kinematics of metal flow during twist extrusion investigated with a new experimental method, J. Mater. Process. Technol, 209 (2009) 3650-3656.

[8] Z.C. Zhang, K. Manabe, T. Furushima, K. Tada, Development of cyclic rotating bending process for microstructure control of AZ31 Magnesium alloy tube, Advanced Materials Research, (2013) 1956-1960. 